\title{
COMPARISON OF EXTRACORPOREAL LAPAROSCOPIC ASSISTED APPENDECTOMY WITH CONVENTIONAL LAPAROSCOPIC APPENDECTOMY IN UNCOMPLICATED CASES OF APPENDICITIS
}

\author{
Hamir Rajatiya ${ }^{1}$, Hiren Vaidya ${ }^{2}$, Pratik Patel ${ }^{3}$
}

${ }^{1}$ Resident, Department of Surgery, Surat Municipal Institute of Medical Education and Research (SMIMER) Surat, Gujarat, India.

${ }^{2}$ Associate Professor, Department of Surgery, Surat Municipal Institute of Medical Education and Research (SMIMER) Surat, Gujarat, India.

3Resident, Department of Surgery, Surat Municipal Institute of Medical Education and Research (SMIMER) Surat, Gujarat, India. ABSTRACT

\section{BACKGROUND}

Appendectomy is the most commonly performed intra-abdominal operation. The study was conducted to compare extracorporeal laparoscopic assisted appendectomy with conventional laparoscopic appendectomy in uncomplicated cases of appendicitis.

\section{MATERIALS AND METHODS}

This is a randomized controlled trial conducted in a tertiary care hospital from August 2014 to July 2016 in cases diagnosed of appendicitis. All cases which underwent laparoscopic appendectomy were divided in to two groups, Group A (Extracorporeal laparoscopic assisted appendectomy) and Group B (Conventional laparoscopic appendectomy). Intra-operative and post-operative findings were compared between two groups. The sample size estimation was also done at convenience.

\section{RESULTS}

In both the groups, time of reversal of anaesthesia was comparable (P 0.348). In group A, mean duration of surgery (28.78 \pm 16.155 minutes) was significantly ( $p<0.01)$ lesser than group B $(42.63 \pm 17.23$ minutes). Only one patient in group B had post-operative complication in the form of fever (more than 100 $\mathrm{F}$ ) for first two days. In group A, mean duration of anaesthesia and mean duration of hospital stay were significantly lower than group B $(\mathrm{p}<0.01)$. In Group A, mean Visual Analog Score for post-operative pain was significantly lower than group B $(\mathrm{p}<0.01)$.

\section{CONCLUSION}

Extracorporeal laparoscopic assisted appendectomy is better in terms of operative time and post-operative hospital stay compared to conventional laparoscopic method.

\section{KEY WORDS}

Extracorporeal Laparoscopic Assisted Appendectomy, Post-operative Complications, Appendicitis.

HOW TO CITE THIS ARTICLE: Rajatiya H, Vaidya H, Patel P. Comparison of extracorporeal laparoscopic assisted appendectomy with conventional laparoscopic appendectomy in uncomplicated cases of appendicitis. J. Evolution Med. Dent. Sci. 2018;7(48): 5170-5173, DOI: $10.14260 /$ jemds/2018/1147

\section{BACKGROUND}

The lifetime risk of developing appendicitis is $8.6 \%$ for males and $6.7 \%$ for females, with the highest incidence in the second and third decades. ${ }^{1}$

Laparoscopic Appendectomy (LA) is preferred over the open method due to its inherent advantages. ${ }^{2}$ Over the past decade, the outcomes of laparoscopic appendectomies have compared favourably to those for open appendectomies because of decreased pain, fewer postoperative complications, shorter hospitalization, earlier mobilization, earlier return to work, and better cosmesis.3, 4, 5 However, despite these advantages, efforts are still being made to decrease abdominal incision and visible scars after laparoscopy. The technique we have described, allows surgeons to use the advantages of the laparoscopic method including visual diagnosis, less postoperative pain, and quicker return to work.

'Financial or Other Competing Interest': None.

Submission 03-09-2018, Peer Review 08-11-2018,

Acceptance 15-11-2018, Published 26-11-2018.

Corresponding Author:

Dr. Hamir Rajatiya,

To. Nagichana, TA. Mongrol,

Dist. Junagadh, Gujarat, India.

E-mail: drhamirrajatiya@gmail.com

DOI: $10.14260 /$ jemds $/ 2018 / 1147$

The laparoscopic-assisted appendectomy requires less operating room time and is less costly than the traditional intracorporeal laparoscopic treatment. In essence, it offers the advantages of both the laparoscopic and the open techniques. Ours is an initial study to assess the practicality of two-port laparoscopic appendectomy and to compare the results with the conventional three-port laparoscopic appendectomy.

\section{Objectives}

The objective of the study was to assess the feasibility, effectiveness, safety and complications of extra corporeal Laparoscopic assisted Appendectomy over conventional Laparoscopic Appendectomy.

\section{MATERIALS AND METHODS}

The Randomized controlled trial is conducted under the department of surgery in our hospital from August 2014 to July 2016. All diagnosed cases of appendicitis admitted in department of surgery were assessed for inclusion and exclusion criteria. The sample size estimation was also done at conveniences.

\section{Inclusion Criteria}

All the patients diagnosed with Appendicitis (based on clinical examination and USG findings) irrespective of age and 
gender, without any complication (In form of appendicular mass or appendicular abscess) were included in the study.

\section{Exclusion Criteria}

All Patients with one or more of the following criteria were excluded from the study-

1. Any extensive lower abdominal surgery, prior preperitoneal surgery.

2. Severe local inflammation.

3. Anticipated bleeding (Cutaneous).

4. Obesity.

5. Pregnancy.

All the eligible cases were explained about the study, potential risk and benefit of the study. A written consent was taken in vernacular language. Those cases who gave consent were alternatively assigned to any one of the intervention group.

They were randomized using computer generated random numbers and allocated into two groups, there were two study groups- Group A and Group B. Cases in Group A underwent Extracorporeal laparoscopic assisted appendicectomy. Cases in Group B underwent Conventional laparoscopic appendicectomy.

Information regarding demography, routine laboratory investigations and ultrasonographic features were collected from all cases before the surgical procedure.

After completion of surgery duration of surgery, duration of anaesthesia, duration of post-operative hospital stay, intraoperative or post-operative complications, postoperative pain and post-operative analgesics requirements, post-operative morbidity and conversion of laparoscopic to open surgery were noted.

Duration of surgery was defined as the time between applying skin incision upto closure of skin incision.

\section{Post-operative pain was measured by Visual Analog Scale} at four points of time-

1. Immediate post-operative

2. After 6 hours of operation

3. After 12 hours of operation

4. After 24 hours of operation.

All cases were followed up for 2 weeks and were assessed for any complication or morbidity

\section{Ethical Issues}

Study was conducted after permission by institutional ethics committee (IEC) and the informed written consent was obtained.

\section{Statistical Analysis}

Descriptive statistical analysis has been carried out in the present study. Results on quantitative data are presented in mean \pm standard deviation and results on qualitative data are presented in percentage (\%). Significance is assessed at 95\% level of significance. Student $t$ test (two tailed, independent) has been used to find the significance of study parameters on continuous scale between two groups on metric parameters. Chi-square test, Fisher Exact test and Yate's correction has been used to find the significance of study parameters on categorical scale between two groups.

\section{Statistical Software}

Data analysis was done using open EPI software. Microsoft Word and Microsoft Excel had been used to generate graphs, tables etc.

\section{Technique used for Extracorporeal Laparoscopic} Assisted Appendectomy

The surgeon and the camera surgeon both stood on patient's left side. The surgeon was on the left side of camera surgeon as well. Monitor was on patient's right side. Scrub nurse with trolley on left foot end. After exteriorization of the appendix in group A, assistant (Camera surgeon) switched to patient's right side. For group B, whole of the procedure was completed with same theatre layout.

Peritoneal cavity was accessed by open method by a 10 $\mathrm{mm}$ incision just below the umbilicus and a target pressure of $10 \mathrm{mmHg}$ was reached using Carbon dioxide gas. Peritoneal cavity and organs were inspected. Another $10 \mathrm{~mm}$ trocar was introduced in right iliac fossa depending upon the position of the appendix after Trendelenburg position and $20^{\circ}$ right up tilt to the patient. Appendix was exteriorized from right iliac fossa port up to its base with a part of caecal wall. Appendicectomy was performed outside the abdomen. Mesoappendix was divided in-between ligatures. After the appendix was skeletonised to its base, it was ligated close to its base using polyglactin 2-0 and divided. Povidone iodine was applied on the stump which was not buried. Caecum was pushed into the abdomen and pneumoperitoneum was again created. Laparoscope was once again introduced to check for haemostasis and to ensure complete appendectomy. Both ports were closed in two layers.

\section{RESULTS}

Total 84 eligible cases were reported during the study period and out of that $80(95.2 \%)$ cases had given consent for the study. Out of 80 cases, 40 were assigned to Group A (Extracorporeal laparoscopic assisted appendicectomy) and 40 cases were assigned to Group B (Conventional laparoscopic appendicectomy).

\begin{tabular}{|c|c|c|c|c|c|c|}
\hline \multirow{2}{*}{ Characteristics } & \multicolumn{2}{|c|}{$\begin{array}{c}\text { Group A } \\
(\mathbf{n = 4 0 )}\end{array}$} & $\begin{array}{c}\text { Group B } \\
(\mathbf{n = 4 0 )}\end{array}$ & $\begin{array}{c}\text { Total } \\
\text { Patients }\end{array}$ & \multirow{2}{*}{$\%$} \\
\cline { 2 - 5 } & Cases & $\mathbf{\%}$ & Cases & $\mathbf{\%}$ & & \\
\hline Age in years & & & & & & \\
\hline $11-20$ & 16 & $40 \%$ & 06 & $15 \%$ & 22 & $27.50 \%$ \\
\hline $21-30$ & 13 & $32.5 \%$ & 22 & $55 \%$ & 35 & $43.75 \%$ \\
\hline $31-40$ & 07 & $17.5 \%$ & 09 & $22.5 \%$ & 16 & $20.00 \%$ \\
\hline $41-50$ & 04 & $10 \%$ & 03 & $7.5 \%$ & 07 & $08.75 \%$ \\
\hline \multicolumn{7}{|c|}{ Table 1. Age Distribution of Patients } \\
\hline
\end{tabular}

Mean age (Mean \pm SD) for group A is $25.98 \pm 9.635$ years and for group B is $27.45 \pm 7.694$ years. Almost two-third of the patients studied were in the second and third decade of life with the lowest age being 14 years and highest being 45 years. 


\begin{tabular}{|c|c|c|c|c|c|c|}
\hline \multirow{2}{*}{ Sex } & \multicolumn{2}{|c|}{$\begin{array}{c}\text { Group A } \\
(\mathbf{n = 4 0 )}\end{array}$} & \multicolumn{2}{c|}{$\begin{array}{c}\text { Group B } \\
(\mathbf{n = 4 0 )}\end{array}$} & $\begin{array}{c}\text { Total } \\
\text { Patients }\end{array}$ & \multirow{2}{*}{$\%$} \\
\cline { 2 - 5 } & Cases & $\mathbf{\%}$ & Cases & $\mathbf{\%}$ & & \\
\hline Male & 28 & $70 \%$ & 24 & $60 \%$ & 52 & $65 \%$ \\
\hline Female & 12 & $30 \%$ & 16 & $40 \%$ & 28 & $35 \%$ \\
\hline \multicolumn{6}{|c|}{ Table 2. Gender Distribution of Patients } \\
\hline
\end{tabular}

Total number of males in the study was 52 and female was 28. Group A included $70 \%$ males and $30 \%$ females. Group B included $60 \%$ males and $40 \%$ females.

\begin{tabular}{|c|c|c|c|c|c|}
\hline \multirow[t]{2}{*}{ Variables } & \multicolumn{2}{|c|}{ Group A $(n=40)$} & \multicolumn{2}{|c|}{$\begin{array}{c}\text { Group B } \\
(n=40)\end{array}$} & \multirow{2}{*}{$\begin{array}{c}\mathbf{P} \\
\text { value }^{*}\end{array}$} \\
\hline & Mean & SD & Mean & SD & \\
\hline $\begin{array}{c}\text { Time of Reversal } \\
\text { (minutes) }\end{array}$ & 4.38 & 2.141 & 4.77 & 1.557 & 0.348 \\
\hline $\begin{array}{c}\text { Duration of } \\
\text { Surgery (minutes) }\end{array}$ & 28.78 & 16.155 & 42.63 & 17.23 & 0.0003 \\
\hline $\begin{array}{c}\text { Duration of } \\
\text { Anaesthesia } \\
\text { (minutes) }\end{array}$ & 40.06 & 17.42 & 54.1 & 18.2 & 0.0007 \\
\hline $\begin{array}{l}\text { Duration of } \\
\text { Hospital Stay } \\
\text { (days) }\end{array}$ & 1.5 & 1.285 & 2.65 & 1.108 & $<0.001$ \\
\hline Th & & & 1 & thes & \\
\hline
\end{tabular}

$\mathrm{SD}=$ Standard Deviation; *Unpaired $\mathrm{t}$ test applied for calculation of $p$ value.

In group A time of reversal of anaesthesia was $4.38+/-$ 2.14 minutes while in group B it was $4.77+/-1.55$ minuets. There is no significant difference in time of reversal in both the group (p 0.348).

In group A, mean duration of surgery was 28.78 minutes and in group B mean duration of surgery was 42.63 minutes. There is significant difference in duration of surgery in both group ( $P$ 0.0003) indicating that duration of surgery was significantly lower in group A compared to group B.

Intra-operative complication was not seen in any of the cases in group A whereas one patient in group B had an intra operative complication in the form of ruptured appendix. Only one patient in group B had post-operative complication in the form of fever (More than $100^{\circ} \mathrm{F}$ ) for first two days.

In group A, mean duration of anaesthesia was 40.60 minutes and in group B mean duration of anaesthesia was 54.10 minutes. There is significant difference in duration of Anaesthesia in both group (P 0.0007) indicating that duration of Anaesthesia was significantly lower in group A compared to group B.

In group $A$, mean duration of hospital stay was 1.50 days and in group B, mean duration of hospital stay was 2.651 .108 days. There is significant difference in duration of hospital stay in both group (P 0.001) indicating that duration of hospital stay was significantly lower in group A compared to group B.

\begin{tabular}{|c|c|c|c|c|c|}
\hline Visual Analog & \multicolumn{2}{|c|}{ Group A (n=40) } & \multicolumn{2}{|c|}{ Group B (n=40) } & p Value \\
\cline { 2 - 7 } Scale (VAS) & Mean & SD & Mean & SD & \\
\hline $\begin{array}{c}\text { Immediately } \\
\text { postoperative }\end{array}$ & 3.63 & 0.667 & 4.18 & 0.501 & $<0.0001$ \\
\hline After 6 hours & 2.75 & 0.707 & 3.75 & 0.588 & $<0.0001$ \\
\hline After 12 hours & 1.85 & 0.662 & 2.80 & 0.516 & $<0.0001$ \\
\hline After 24 hours & 0.75 & 0.707 & 2.65 & 1.122 & $<0.0001$ \\
\hline
\end{tabular}

Table 4. Post-Operative Pain
In Group A, mean VAS was $3.63 \pm 0.667$ immediate postoperative, $2.75 \pm 0.707$ after 6 hours, $1.85 \pm 0.662$ after 12 hours and $0.75 \pm 0.707$ after 24 hours of surgery. In Group B, mean VAS was $4.18 \pm 0.501$ immediate postoperative, $3.75 \pm 0.588$ after 6 hours, $2.80 \pm 0.516$ after 12 hours and $2.65 \pm 1.122$ after 24 hours of surgery. Mean VAS was significantly lower in group A compared to Group B at all different time interval ( $p$ value $<0.0001$ )

\section{DISCUSSION}

Although the technique of laparoscopic appendectomy using three ports has gained acceptance and popularity, there are still reservations on its technical difficulties and cost. Inspired by these arguments, we thought of using the two ports laparoscopic assisted appendectomy in adults. The procedure is simpler, cost effective and has all the advantages of minimally invasive and open surgery. 6,7 In case of conversion to the open procedure the incision for the port in the right iliac fossa can be used for a conventional ('McBurney') incision. Two port laparoscopic appendectomies has better option than three port and is now considered to be a safe and excellent alternative to open appendectomy.

It takes more time to divide mesoappendix, to ligate or to clip appendicular artery and to ligate the base of appendix. Whereas all these steps can be done very quickly when done outside the abdomen with hands in a way it is done in open appendectomy. As the number of ports are also reduced it takes lesser time to insert and remove the ports and to suture the wound.

The less post-operative pain in group A is probably related to less operative trauma as only two ports are used. The other reason could be the less duration of pneumoperitoneum and shorter duration of surgery.

The cost of treatment was less as the former required lesser amount of carbon dioxide due to shorter duration of pneumoperitoneum and the amount of anaesthetic drugs required was also less because of shorter duration of surgery. The cost of endoloop was also saved, there was less requirement of post-operative analgesia and lesser postoperative hospital stay saved money spent by patients on daily hospital expenditure.

\section{CONCLUSION}

Extra corporeal laparoscopic assisted appendectomy is a promising method of doing laparoscopic appendectomy. In our study, highest incidence of appendicitis was in second and third decades of life. The mean duration required to perform extra corporeal laparoscopic assisted appendectomy is significantly less than the time required to perform conventional laparoscopic appendectomy. In cases with adhesions, exteriorising the appendix through port site in right iliac fossa is difficult. Extra corporeal laparoscopic assisted appendectomy is better in terms of operative time and post-operative hospital stay, although there is not much difference between either intra-operative or post-operative complications. Extra corporeal laparoscopic assisted appendectomy could be the choice of procedure for interval appendectomy and selective cases of acute appendicitis as compared to open or conventional procedures. After gaining experience in the technique and acquisition of proficiency, this technique could be applied to acute and complicated cases also. 


\section{REFERENCES}

[1] Addiss DG, Shaffer N, Fowler BS, et al. The epidemiology of appendicitis and appendectomy in the United States. Am J Epidemiol 1990;132(5):910-25.

[2] Li X, Zhang J, Sang L, et al. Laparoscopic versus conventional appendectomy: a meta-analysis of randomized controlled trials. BMC Gastroenterol 2010;10:129.

[3] Eypasch E, Sauerland S, Lefering R, et al. Laparoscopic versus open appendectomy: between evidence and common sense. Dig Surg 2002;19(6):518-22.

[4] Yagnik VD, Rathod JB, Phatak AG. A retrospective study of two-port appendectomy and its comparison with open appendectomy and three-port appendectomy. Saudi J Gastroenterol 2010;16(4):26871.
[5] Garbutt JM, Soper NJ, Shannon WD, et al. Meta-analysis of randomized controlled trials comparing laparoscopic and open appendectomy. Surg Laparosc Endosc 1999;9(1):17-26.

[6] Valioulis I, Hameury F, Dahmani L, et al. Laparoscopic assisted appendectomy in children: the two trocar technique. Eur J Pediatr Surg 2001;11(6):391-4.

[7] Nicholson T, Tiruchelvam V. Comparison of laparoscopic assisted appendectomy with intracorporal laparoscopic appendectomy and open appendectomy. JSLS 2001;5(1):47-51. 